\title{
Exploring gamification design elements for mental health support
}

\author{
Emma Nuraihan Mior Ibrahim*, Nurulfitrie Jamali and Ahmad Iqbal Hakim Suhaimi \\ Faculty of Computer and Mathematical Sciences, Universiti Teknologi MARA, 404500, Shah Alam, Selangor, \\ Malaysia
}

Received: 5-October-2020; Revised: 25-January-2021; Accepted: 27-January-2021

(C)2021 Emma Nuraihan Mior Ibrahim et al. This is an open access article distributed under the Creative Commons Attribution (CC BY) License, which permits unrestricted use, distribution, and reproduction in any medium, provided the original work is properly cited.

\begin{abstract}
Mental health is defined as a condition of a person's well-being in coping with the stress of life. Mobile apps that used gamification has been proven effective as a mental health intervention in the form of therapeutic tool for counseling and mental therapy. Entertainment content of video games has been shown to improve mood, enhances motivation, and reduce stress/emotional relief. Though the benefits of gamification as an intervention tool for assisting people during life difficulties were widely researched, yet less research focused on what are the significant gamification elements in a game design that can influence one mental health state. In fact, research on mental health and gamification in Malaysia is relatively new and limited. This research aims to identify the significant gamification design elements which influence the user in overcoming their mental health problems through game playing and game interaction. The scope of this research involved a focus group consists of five (5) users with anxiety issues and with more than two years' experience in playing entertainment games to elevate their anxiety problems. The research methodology was conducted using qualitative approaches via narrative inquiry (in-depth interview) to understand the user's experiences and interaction with the entertainment game app. The results were consolidated using a thematic analysis approach. From the research findings, four (4) design themes emerged, there are 1) storytelling 2) challenge 3) engagement, and 4) point and reward. Based on the participant's feedback the design element of engagement was discovered as the most significant to enhance passion and emotional involvement in participation and completion of levels/challenge in game interaction. In conclusion, the research has identified four (4) gamification design elements that drive possible emotional changes of the participants during their interaction with the game app. As the research was exploratory in nature with a limited number of respondents; for future work, we proposed a mixed-method approach to understand each design element and its relationship through prototype building and theoretical model validation.
\end{abstract}

\section{Keywords}

Gamification, Mental health, Design elements, Thematic analysis.

\section{Introduction}

The World Health Organization defined mental health as "a state of well-being in which the individual realizes his or her own abilities can cope with the normal stresses of life, can work productively and fruitfully, and can contribute to his or her community" [1]. Mental health disorder becomes a global public health issue nowadays. It has become a crucial agenda for Sustainable Development Goals (SDG). The goal is to transform the world by ensuring healthy lives and promote well-being which includes mental health for all ages by 2030 [2].

*Author for correspondence

114
The Ministry of Health (MOH) Malaysia has conducted a National Health and Morbidity Survey 2017 [3] which shows attempting suicide and lacking social connections are the main factors that contribute to mental health issues among teenagers age 13 years old to 17 years old. Globally, numerous news showed an alarming case of depression and anxiety. Moreover, the existence of the internet and Social Network Service (SNS) has become a medium for the public to cyberbully the victim thus affecting their mental health and suicidal thoughts [4].

For example, in Kuching Malaysia, a similar issue has affected a 16 years old girl who killed herself after her Instagram followers voted for her death in one of her Instagram Story polls [5]. Due to this, the Malaysian Communication and Multimedia Commission (MCMC) have stated a statement in 
advising the social media user to be more vigilant in any miserable posting to avoid the same incident reoccurring.

In Malaysia, few mental health foundations provide support both spiritual and clinical treatment namely Mental Illness Awareness and Support Association (MIASA) or Pusat Komuniti Kesihatan Mental Putrajaya (MENTARI) aid mental illness patient in psychosocial interventions including counselling, psychotherapies and psychoeducation [6]. The integration of spiritual and health practice has become the common approaches for facilitating healing and recovery. Despite the biological psychiatry treatment advancement, the reception on mental health diagnosis and treatment in Malaysia is relatively low. This is due to the cultural beliefs that psychiatric illness carries a highly negative connotation and it is called as "sakit mental" which refers as crazy or madness [7, 8]. For Malaysians, mental illness is still considered as taboo that affects the degree of openness which has contributed $62.3 \%$ of the sufferer remained untreated [9]. This has clearly stated how urgent the mental health issue in Malaysia should be enlightened and take as a serious matter.

Based on past literature, researchers have started to explore digital technologies intervention towards mental health support [10-13] especially in computer and game industry [14]. It is believed technology interventions like sensor-related technologies, games, virtual reality, application on smartphones like ehealth and m-health can foster learning, enhance motivation and promote cognitive and behavioral change [14-16] thus extending the scope of clinical treatment [17]. Meanwhile, several literatures stressed on game and gamification approach to mental health recovery where it exploit various processes of engagement in dealing with individuals through educating, motivating and as health support $[18,19]$. According to [20] games that led to positive well-being should consist of several elements like positive emotion, engagement, relationship, meaning and accomplishment while playing video games could distract oneself from stress and improve social relations by having something to talk about [21-23]. Game designer and researchers have studied the practicality of commercial games or known as "casual games" for mental health treatment. Games such as "Lock-On: Modern Air Combat", "Tetris" were found to decrease traumatic flashbacks [24-26] and "The Sims Life Stories' enable engagement and emotion regulation among adolescents [27].
However, effective designs of digital interventions for mental health necessitate several considerations [22] which require new models of behavioral understanding related to the patient's experiences rather than based on the traditional structured psychotherapy model [23]. Furthermore, most of the research was handled in quantitative methods such as surveys, questionnaires, comparative analysis to investigate the patent and behavior of mental illness patients and its impact on the games [28]. However, the researcher also criticized these approaches as it lacks a direct connection between researchers and participants when collecting data. Problems arise as researchers might overlook the respondent experiences [29]. Besides, most of the research stated above reflected the Western view of understanding, and less research conducted from the Malaysian perspective on how game intervention and its design elements can improve one mental health being. Therefore, this research is aimed to explore the gamification elements embedded in an entertainment game app to propose a user-generated design requirement for future game development in supporting mental health issues.

In guiding this research, the researcher formulated two research questions and research objectives based on the issues discussed above:

Research Questions:

1. How playing games influence a user's experiences for improving mental health and well-being?

2. Which gamification design elements in a game application are significant for improving a user's mental health and well-being?

Research Objectives:

1. To investigate the user's experiences in gameplaying for improving mental health and wellbeing.

2. To identify the gamification design elements that can help improves mental health and well-being.

\section{Literature review}

According to the Mental Health Foundation [30], there are several types of common mental health problems which include depression, Generalized Anxiety Disorder (GSD), panic disorder, ObsessiveCompulsive Disorder (OCD). Depression is a common mental illness with low mood, loss of interest or enjoyment, reduced motivation, low selfesteem, disturbed sleep or appetite, and poor concentration. These problems of depression become chronic if it is coming with anxiety symptoms. In the 
past, the prevention of mental health problems could be enhanced through a non-technological approach such as counseling, talking therapy, meditation, and social group support. However, with technological advancement, the use of devices and apps has gained immense prominence in promoting self-improvement across various fields such as food, mindfulness and concentration, and stress reduction.

\subsection{Game as technological intervention}

\subsubsection{Game, serious game and gamification}

Today, gaming has become a ubiquitous therapy for serious purposes such as education [31] and health [32]. Game is defined as a form of play concerning rules, fun, and competition [33, 34]. Whereas, a serious game is a game with a serious primary purpose to train, improve player performance, and their cognitive abilities levels which are knowledge, skills, and behavior [35, 36]. Serious games also offer a significant number of advantages, such as making players feel responsible for their actions, mixing high-quality content, showing great involvement, and transforming errors into learning elements [37, 38] and is usually applied in the domain of learning, education, military training, health, and advertising. In the literature, the term gamification refers to digital game-based learning that create user engagement, influence action, encourage learning, and overcoming difficulties [39]. The design elements of gamification consist of narrative, feedback, reward system, conflict, cooperation, rules, interaction, and interactivity among other players which enhances the lives of individuals [36]. Gamification also aims at uniting functionality and engagement [40], increasing usability [41], productivity and satisfaction [42], creating more enjoyable experiences [43], and producing positive business impact [40].

The health research community has shown considerable interest in gamification research for its possibility to heighten user engagement through health intervention and behavioral change stimulation. A recent study from [18] on the relationship of serious gaming and gamification stated that depression treatment specificities are linked to the concept of what assist tasks should be gamified or included in the serious game. Today major categories of applied games have been designed namely cognitive behavior therapy-based games, virtual reality, augmented reality, mixed reality, exergames, entertainment games, biofeedback, and cognitive training games which said could help a player regulate their emotions [44, 45].
The goal of expanding current gaming therapy is to increase user interaction and engagement; to improve efficacy as well as emulate mental health challenges like overcoming frustration and create training support for the cognitive challenge [46].

\subsection{Theory-driven of gamification model}

The research adopted the gamification design model from Huang, hew [47] as the theoretical grounding Based on the gamification design model, there are five (5) motivation elements that become the features for user-cantered game design development.

\subsubsection{Goals}

In a game content, gamification design elements like badges and points can be used to set up realistic goals. To improve the participant's well-being, the reward system was very helpful to improve the participant's motivation and driven their attention to goal-related activities [47]. By having a new goal and aim to achieve, the participant's emotion was shifted to the games [48].

\subsubsection{Challenge}

According to [49], game designers must allow immersive playing experience for the player to be able to engage with the game. Immersive experiences can create extremely personal and emotional moments. Immersion clearly has links to the notion of flow and cognitive absorption where it is the key to a good game experience [50]. The features of the challenge had brought the participants to have their own discovery, role-playing, customization and escapism characteristics in a game, immersion will be developed, and act as therapy for the player [51].

2.2.3Access

Access is offering participants to have their own exploration in gaming. Design elements such as levelling up direct the participants to build competency in a game. Computer games should have something to offer in relation to the naturally given exploration and when players look more closely at some of the properties of computer games, they find compelling evidence that this can be helpful to their life [47].

2.2.4Feedback

Gamification or serious games have these common elements including point, badges (digital badges are a validated performance, ability, value, or motivation pointer that can be received in many learning environments); leaderboard, quest, and challenge (supports the adventurous engagement and activates analytical thinking skills by establishing the elements of searching and sighting ); and avatar (players representatives that mirror their goals, weaknesses, and various personas they show in life) [52]. These 
features had acted as the feedback for every task that they had carried out and could increase the engagement as they learn to self-evaluation and selfcorrection from the status stated through the features mentioned [53, 54].

2.2.5 Engagement and collaboration

Fun element is usually found in a video game content. Its purposes are to gauge user's the attention and entice their positive enthusiasm [55]. According to [44] engagement can be identified in five key dimensions which are achievement, exploration, sociability, domination, and immersion. For example, a difficult challenge may inverse engagement and trigger boredom, diversion, anxiety, and frustration. In addition, with engagement and collaboration features it enables team players to work together to achieve similar goals which in turn made them feel connected and giving positive reinforcement [56].

\section{Methodology}

\subsection{Qualitative approaches}

For this research, a qualitative study is used to explore the role of gaming in overcoming one mental health issues and to identify the gamification elements that trigger their emotions while playing. Further sections explained the research approaches.

3.1.1Focus group and pre-assessment questionnaire Focus group can significantly contribute to the study by having social representations that allows for questions and answers on what a group thinks, how, and why does it involve. A total of five participants (two males and three females) voluntarily participated in this research. The participants were recruited through social media advertisements posted on IG and FB about the study. For this research, the researcher only recruited participants within the youth category age ranging from 20 to 24 years old; who is diagnosed with depression and has more than two years' experience in entertainment game interaction as part of overcoming mental health issues (Table 1). The participants were also given a preassessment questionnaire. A pre-assessment questionnaire is an instrument for fully assessing the construct of interest of the participants [57]. It also helps in evaluating participant attitude towards the research participation either to withdraw or continue as the content might be quite sensitive. The preassessment questionnaire is the screening test questions where the participant is being diagnosed about depression severity (Table 1) and the questions are adopted from Personal Health Question-9 (PHQ9) which was approved by the clinician [58]. In order to understand the respective participant persona, a user profile (Figure 1) was created to give the researcher general insights into their characteristics and experiences followed by a brief interview (Table 2).

Table 1 Participants profiles

\begin{tabular}{llllll}
\hline P(n) & M/F & Age & Profession & $\begin{array}{l}\text { Time spent/ } \\
\text { Day on game }\end{array}$ & Depression severity \\
\hline P1 & M & 23 & Sale Consultant & $>2 \mathrm{~h}$ & Moderately severe depression \\
\hline P2 & M & 22 & Student & $>2 \mathrm{~h}$ & Moderately severe depression \\
\hline P3 & F & 24 & Neuroscientist & $>3 \mathrm{~h}$ & Severe depression \\
\hline P4 & F & 20 & Student & 30 minutes daily & Severe Depression \\
\hline P5 & F & 23 & Teacher & $>4 \mathrm{~h}$ & Severe depression \\
\hline
\end{tabular}

Table 2 Interview questionnaire

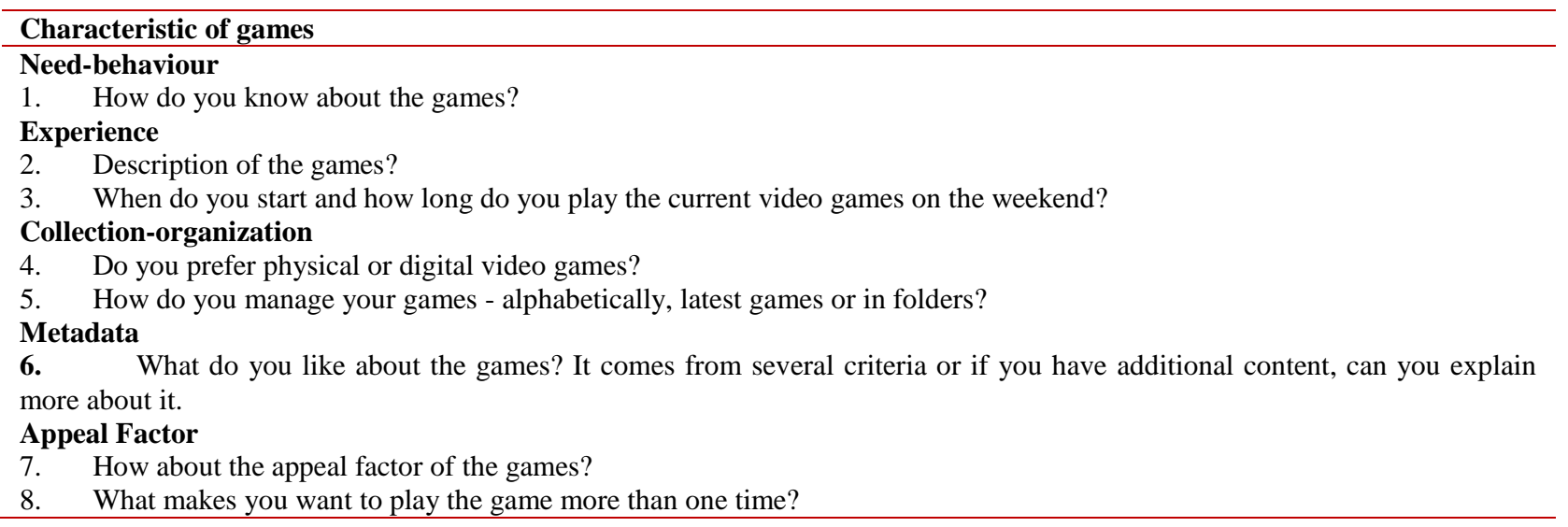




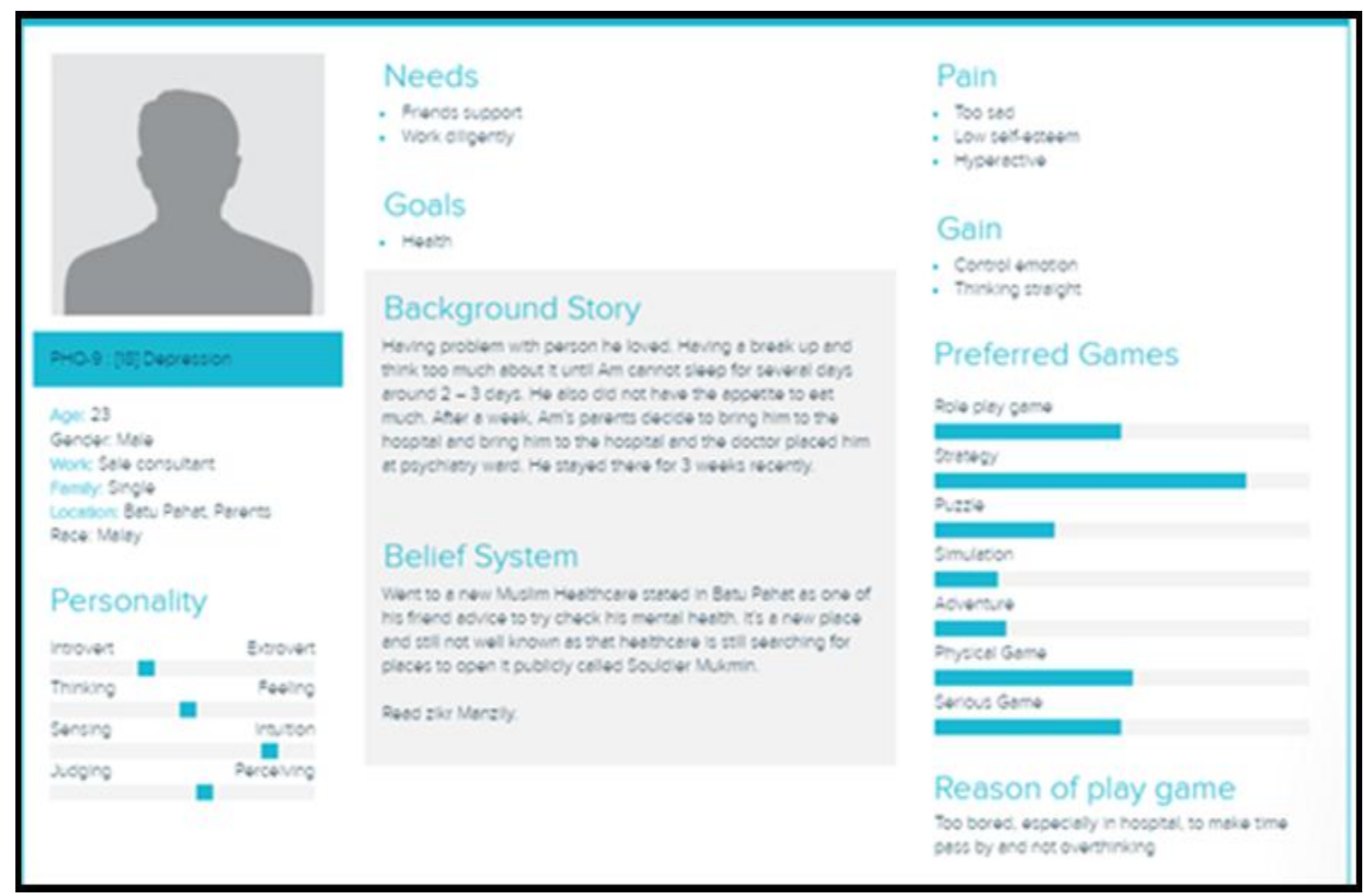

Figure 1 User profile template

\subsubsection{Narrative inquiry}

After the completion of the initial interview, an indepth interview was conducted to understand the needs and behavior of the game. A set of questions that consist of 28 questions (Table 3) has been prepared regarding the game's characteristics which were adapted and modified from "The Wellbeing of Games" [59] and "CodeBook" [60]. The narrative inquiry approach is used to understanding and inquiring into the experience through collaboration between the researcher and the participants from the focus group session. As in interviews, researchers will listen to participant's stories and acknowledge the mutual construction of the research relationship. The narrative inquiry begins by asking the participants to tell their stories by responding to the interview questions. Content analysis is used to transcribe the interview and the accuracy of the summary report is validated by crosschecking the content with the participants.

Table 3 Interview questions on games characteristics adapted and modified from [59],[60]

\section{Characteristics of games}

\section{Interview outline:}

\section{General}

1) Can you list down what are your favorite games?

2) Why these mentioned games are your favorite?

3) What kind of game played-devices do you currently own?

4) When did you start to be interested in playing video games and for how long has it lasts?

5) How long do you spent playing alone vs playing with other counterparts/peers?

6) What kind of place that you feel comfortable playing video games?

7) What are the main reasons do you play video games?

8) Between physical and digital games, which do you prefer and why?

9) Why did you play video games during your life difficulties?

10) Do games provide a well-being to you?

11) In what way does it help you?

Questions about physical video games:

12) How many types of physical video games do you play in an average week? 


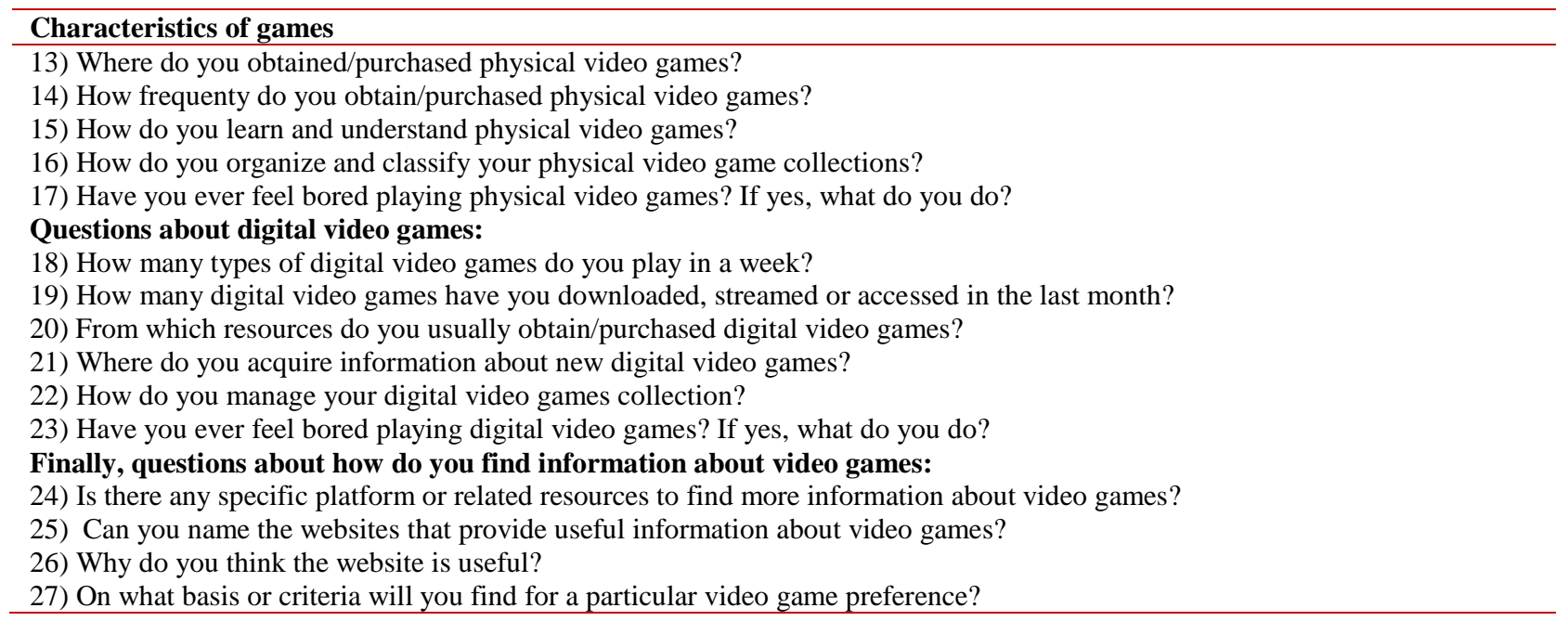

\subsubsection{Thematic analysis}

Thematic analysis is the method of examining the topic, ideas, patterns, themes that emerged from qualitative data such as texts [61]. The pattern of the data that has been accumulated and classified provides useful meaning embedded to it which can potentially provide a rich and detailed insight on one particular aspect. The thematic analysis process has six steps and is adapted from [62]. The first step is to familiarize with the data which means the researcher needs to go through the interview data (audio/video) and start marking initial ideas for codes to describe the content. The second step is to generate initial codes. A code is a description assigned to identified interesting data to the researcher. This will be the initial step to organize the codes into meaningful themes. The third step is searching for themes whereby the researcher will start visualize the relationship between the codes and potential themes. The fourth step is to review the themes derived in step three. The researcher will consolidate between the codes and themes and their meaning within the context of the study. Themes can be single or multiple themes. The fifth step is to define and naming the themes. The researcher will rename and describe the themes and sub-themes (if applicable) from the previous step. In this step, the researcher will try to describe the essence of the theme, why and how the themes are related and the relation to the research questions.

The sixth step is to produce the report where the researcher will present the summary of the themes. This can be done through visualize presentation, user scenario, or user persona.
The validity of individual themes will be considered by determining the theme accurately which reflects the meaning evident in the data as a whole. Further analysis had been done where the mentioned themes were calculated using a formula to count the frequency of a selected theme repeated by the participants. The number of participants which stated the designated theme during the interview session is shown in column cases (Table 4 ). The percentage $\%$ cases is referring to how many participants cited the designated themes in the interview out of the total number of participants.

$\%$ Cases $=$ Number of participants mentioned the selected theme $\times 100 /$ Total participant

In order to assess the recurrence of the themes found in the analysis, the $\%$ themes were calculated referring to the respective theme found in comparison of all total themes coded in the analysis.

$\%$ Themes $=$ Count of selected theme appearance $\times$ 100/ Total Count of all themes

\section{Results and findings}

Table 4 shows the results of theme frequency where the element of "Challenge" was more significant with $2.25 \%$ higher than the other themes. Also, further discussion with the participants on the outlined themes is done through an interview. This is to verify and reframing its meaning intended. As a result, only one theme was renamed as per revision with the participants as shown in Table 5 where theme "Connectivity" is changed to theme "Engagement". Thematic analysis map is produced in Figure 2 based on the outcome from the emergence of a new theme. A thematic map shows a different set of colors were used for separations of themes; the theme (Parent 
node) has 4 data - green in color; whereas for code (Child node) has 26 data - yellow in color. During this phase, the researcher asked what and why questions to determine what data characteristic and meaning were associated with each theme. For each theme, the researcher writes a detailed analysis based on the narrated story from the participants. At this stage, the researcher consolidated how each theme and entire data set fits together with the theoretical understanding in [47]. In summary based on the thematic analysis, there are four (4) design themes related to gamification elements that were classified. There are: Storytelling, Challenges, Engagement and Points and Award. Below are the details of the explanation based on the narrative inquiry outcome.

\subsection{Storytelling}

Storytelling is an element that is used to transfer the game's event in words, sound, or images by improvisation or embellishment where the elements of the storytelling include plot, characters, and narrative point of view [63]. Every participant has stated gaming platforms have become part of their companion in shifting their emotions. The plot of the story increases their excitement thus became one of the reasons why they chose a particular game. A recent study from [64, 65] stated the difficult life experience is exhausting especially when they need to deal with the terminal illness, thus, the storytelling element brought them to a new 'zone' where the patients could play in a complete focus without thinking much about the meditation. participant one (P1), stated that:

"I watched the trailer of the games that are provided at the app store. If it looks fun, I will download it, I also take into consideration the title, plot, story, graphics of the games, theme, and type of ending. For example, from the Homescape game, I can design a house if I'm winning that level. The Sims is a nostalgia game for me as I can create family, build a dream home just about a real-life experience" - P1

\subsection{Challenges}

Researchers found that a game without challenge will be boring but if it's too challenging, it will cause one's to give up $[66,67]$. However, the statement can be contended by the participant's statement where the types of games that they choose were based on their mood despite the level of difficulty from the games. Participant two (P2) and participant three (P3) stated that:
"Every game that I download should be able to entertain me but based on my mood at that time. If I want to play something relaxing, I will choose Candy Crush, if I feel like I want to ride a car, I will choose a game with speed and different challenge"- P2

"The dimension of the game makes it more real and also the strategy in every game is different. Most of the time my mood only has two. If I want to play for leisure, I would go for FIFA but if I am in need of an outlet, I will play more intense games like Assassin Creed. “- P3

The challenge of the games can be in various forms. According to the participants (P2), (P3), challenges could focus on strategy, shooting, mastering skills, problem-solving, tactical, or intense gaming. These kinds of challenges are said to contribute to their escapism as well as achievement to boost their selfconfidence and self-efficacy $[48,68]$.

\subsection{Engagement}

Engagement provides connectivity with other players in different ways. Interaction between other players in the games is important to win the games. According to [67], communication, cooperation, competition and conflict were included in social behavior. The player excitement level is different when they were playing with friend, non-player character (NPC) or stranger especially for Role Play Games (RPG) like World WarCraft or DOTA 2 [69, 70]. This is supported by participant two (P2) and participant five (P5) comments:

"I also like to play with my friends as I can share what I feel during the game playing and we collaborate together to win the game"- P2

"Playing games actually helped me to build connections and relationships with people, especially people who play the same game as I do. Since I'm not good at making conversation, I actually made some conversation by talking about games to some people around me"- P5

In other cases, the interaction was allowed in dealing with feelings as gaming provides an additional form of support [64]. Examples of games mentioned by the participants are Player Unknown Battleground (PUBG) and Clash on Duty (COD). Multiplayer online games have become popular for users to interact and form relationships through avatar. Some players preferred playing hours in isolation and some place their social relations in a game environment. 


\subsection{Point and reward}

Score and award are the types of reward-related to the feeling of enjoyment which increases intrinsic motivation in winning the games [71]. Participant three (P3) and participant five (P5) commented:

"I can customize my character, and mostly I applied to Assasin Creed game. The things that make me want to play the game more and more is because of my past accomplishments"- P3

"For the Hidden Hotel game, I love those cute things and decorating the hotel. For most of the games, the awarding part is the very fun part. The feeling of satisfaction, relief really help me in counter my problems"- P5

The sense of competency by achieving reward brings enjoyment to users where it can generate the feeling that they are doing well in completing tasks and activities. On top of that, players also managed to face the new challenges as they gained motivation from the rewards. Rewards such as levels increment, points and badges raise the feeling of achieving mastery, autonomy, and a sense of belonging [72, 73].

Table 4 Interview questions on games characteristics

\begin{tabular}{|c|c|c|c|c|c|}
\hline Theme (s) & Description (s) & $\begin{array}{l}\text { Count } \\
\text { (themes) }\end{array}$ & $\begin{array}{l}\text { Themes } \\
(\%)\end{array}$ & Cases & $\begin{array}{l}\text { Cases } \\
(\%)\end{array}$ \\
\hline Storytelling & $\begin{array}{l}\text { Refer to plot of the story, the visual and audio of the } \\
\text { games. }\end{array}$ & 6 & $1.5 \%$ & 4 & $80 \%$ \\
\hline Challenge & Several types of challenges like cooking or shooting. & 9 & $2.25 \%$ & 4 & $80 \%$ \\
\hline Engagement & $\begin{array}{l}\text { The interaction that happened between participant and } \\
\text { other player either through chat in the games or audio. }\end{array}$ & 6 & $1.5 \%$ & 3 & $60 \%$ \\
\hline Point and reward & $\begin{array}{l}\text { Type of rewards like stars, bonus level or interior } \\
\text { designing increase the motivation and enjoyment towards } \\
\text { the game. }\end{array}$ & 7 & $1.75 \%$ & 4 & $80 \%$ \\
\hline
\end{tabular}

Table 5 Emergence of new themes

\begin{tabular}{ll}
\hline Previous theme & New theme \\
\hline Storytelling & Storytelling \\
\hline Challenges & Challenges \\
\hline Connectivity & Engagement \\
\hline Point and Reward & Point and Reward \\
\hline
\end{tabular}

\section{Conclusion and future work}

Based on the objectives, generally, the research seeks to explore (1) why users with mental health issues used entertainment game mobile app as the platform to overcome their problems (2) how they interact with the games, and (3) what gamification design elements of the game mobile app possibly heighten their positive emotions.

Using qualitative methodology, a narrative inquiry was adopted for the in-depth interview approach, and the findings, a thematic analysis was performed to analyze the outcome. The results identified four gamification design elements that are significant in the design of entertainment game mobile app content which are storytelling, challenges, engagement, point, and reward. Among these elements, "engagement" was believed to be more significant from the participant's perspectives as it enables to deliver an experience that is deeply, intrinsically motivating through features like achieving a certain target level of challenge, building up the skills, increase social 121 experience as participants may likely find another player with the same motivation and interests. From the session, all five (5) participants concluded that game playing has become their tool or outlet to distract from life difficulties.

Nevertheless, there are few limitations of the qualitative approach in this research context. The methodology doesn't allow us to measure causality as the findings are solely interpretive in nature thus qualitative research results usually are not statistically presented. As the current research is exploratory in nature focusing on answering the "why" "how" and "what" questions, interviewed with only five (5) respondents and covering solely entertainment-based games mobile app features, hence we cannot make any statistical inference or generalize the outcome to other types of game content.

Therefore, for future work, to further investigate the effect of gamification elements on the user's mental 
well-being, an entertainment-based mobile game prototype needs to be built for testing and validating the proposed gamification elements. Hypothesis and its measurement need to be done to gauge the overall efficiency and effectiveness of the gamification design elements and their influence on one mental health condition. The research also needs to be extended to various mobile game categories for holistic view modeling theoretical development. To understand how the game mobile app acts as a behavioral tool intervention, a comparative study can be done to evaluate the use of technology-based intervention tools vs clinical intervention.

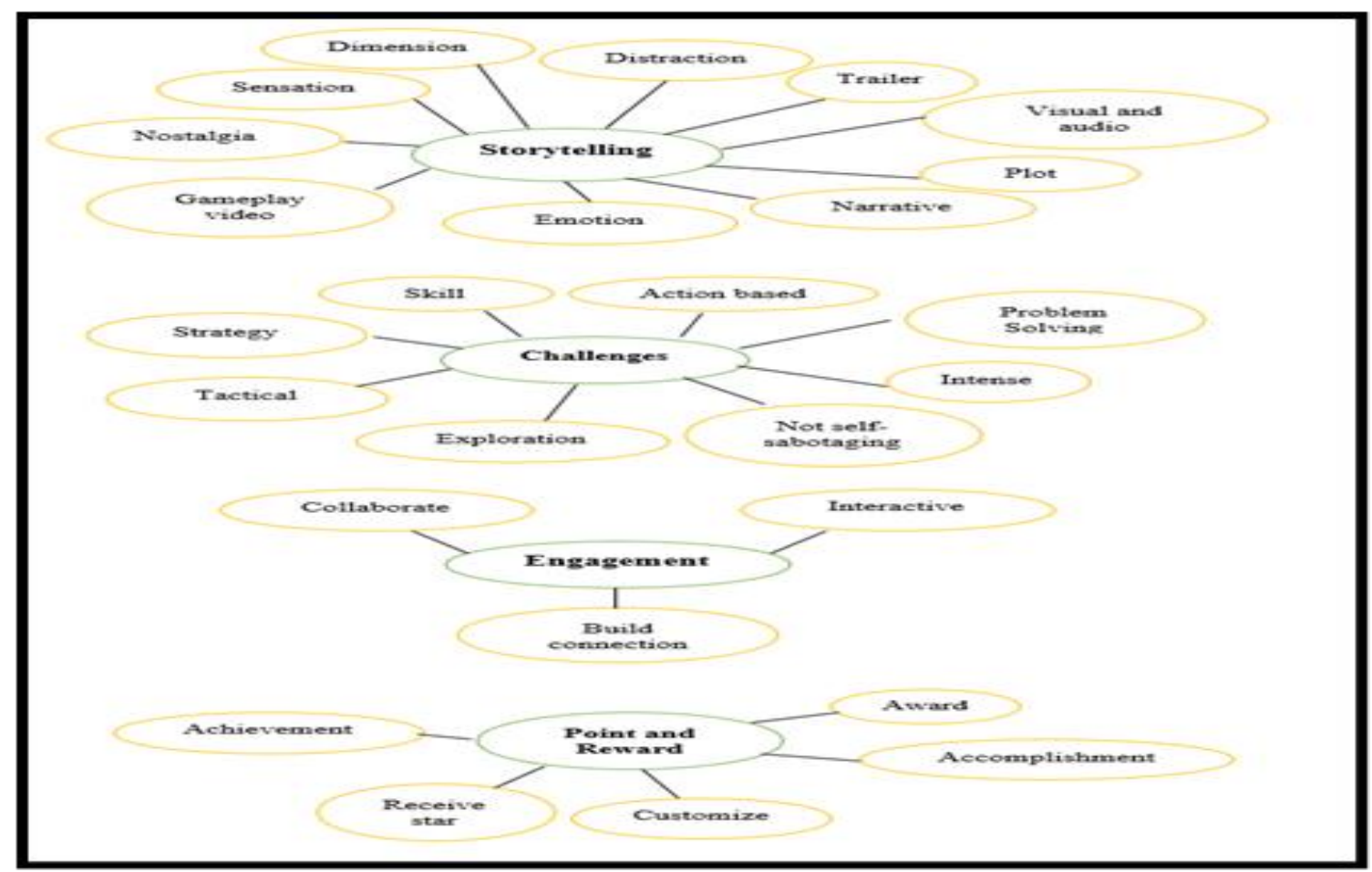

Figure 2 Thematic analysis map

\section{Acknowledgment}

None.

\section{Conflicts of interest}

The authors have no conflicts of interest to declare.

\section{References}

[1] Hosman CM, Jané Llopis E, Saxena S. Prevention of mental disorders: effective interventions and policy options. Geneva : World Health Organization. 2004.

[2] https://www.who.int/maternal_child_adolescent/docu ments/adolescents-health/en/. Accessed 26 September 2020.

[3] http://iku.moh.gov.my/images/IKU/Document/REPO RT/ NHMS2017/ NHMS2017 Infographic.pdf. Accessed 26 September 2020.

[4] Garett R, Lord LR, Young SD. Associations between social media and cyberbullying: a review of the literature. Mhealth. 2016; 2(12):1-7.

[5] https://www.thestar.com.my/news/nation/2019/05/17/ cops-teen-who-committed-suicide-after-instagram- poll-suffered-from-depression/. Accessed September 2020.

[6] https://www.moh.gov.my/moh/resources/Penerbitan/P enerbitan\%20Utama/Annual\%20Report\%20MoH\%20 2017.pdf. Accessed 26 September 2020.

[7] $\mathrm{Ab}$ razak A. Cultural construction of psychiatric illness in Malaysia. The Malaysian Journal of Medical Sciences. 2017; 24(2):1-5.

[8] Razali SM, Najib MA. Help-seeking pathways among Malay psychiatric patients. International Journal of Social Psychiatry. 2000; 46(4):281-9.

[9] Bin Hassan MF, Hassan NM, Kassim ES, Hamzah MI. Issues and challenges of mental health in Malaysia. International Journal of Academic Research in Business and Social Sciences. 2018; 8(12):1685-96.

[10] Alqithami S, Alzahrani M, Alzahrani A, Mostafa A. Modeling an augmented reality game environment to enhance behavior of ADHD patients. In international conference on brain informatics 2019 (pp. 179-88). Springer, Cham.

[11] Iacovides I, Mekler ED. The role of gaming during difficult life experiences. In proceedings of the $\mathrm{CHI}$ 
conference on human factors in computing systems 2019 (pp. 1-12).

[12] Naslund JA, Aschbrenner KA, Araya R, Marsch LA, Unützer $J$, Patel $V$, et al. Digital technology for treating and preventing mental disorders in lowincome and middle-income countries: a narrative review of the literature. The Lancet Psychiatry. 2017; 4(6):486-500.

[13] Lau HM, Smit JH, Fleming TM, Riper H. Serious games for mental health: are they accessible, feasible, and effective? a systematic review and meta-analysis. Frontiers in Psychiatry. 2017; 7:1-13.

[14] Király O, Urbán R, Griffiths MD, Ágoston C, Nagygyörgy K, Kökönyei $G$, et al. The mediating effect of gaming motivation between psychiatric symptoms and problematic online gaming: an online survey. Journal of Medical Internet Research. 2015; 17(4):1-15.

[15] Von Der Heiden JM, Braun B, Müller KW, Egloff B. The association between video gaming and psychological functioning. Frontiers in Psychology. 2019; 10: 1-11.

[16] Ebert DD, Cuijpers P, Muñoz RF, Baumeister H. Prevention of mental health disorders using internetand mobile-based interventions: a narrative review and recommendations for future research. Frontiers in Psychiatry. 2017; 8:1-16.

[17] Fairburn CG, Patel V. The impact of digital technology on psychological treatments and their dissemination. Behaviour Research and Therapy. 2017; 88:19-25.

[18] Fleming TM, Bavin L, Stasiak K, Hermansson-Webb E, Merry SN, Cheek C, et al. Serious games and gamification for mental health: current status and promising directions. Frontiers in Psychiatry. 2017; 7: $1-7$.

[19] Deterding S. The lens of intrinsic skill atoms: a method for gameful design. Human-Computer Interaction. 2015; 30(3-4):294-335.

[20] Jones C, Scholes L, Johnson D, Katsikitis M, Carras MC. Gaming well: links between videogames and flourishing mental health. Frontiers in Psychology. 2014; 5: 1-8.

[21] Liverpool S, Mota CP, Sales CM, Čuš A, Carletto S, Hancheva C, et al. Engaging children and young people in digital mental health interventions: systematic review of modes of delivery, facilitators, and barriers. Journal of Medical Internet Research. 2020; 22(6): 1-16.

[22] Mandryk RL, Birk MV, Lobel A, Van Rooij M, Granic I, Vanden Abeele V. Games for the assessment and treatment of mental health. In extended abstracts publication of the annual symposium on computerhuman interaction in play 2017 (pp. 673-8).

[23] Mohr DC, Weingardt KR, Reddy M, Schueller SM. Three problems with current digital mental health research and three things we can do about them. Psychiatric Services. 2017; 68(5):427-9.
[24] Bowman ND, Tamborini R. Task demand and mood repair: the intervention potential of computer games. New Media \& Society. 2012; 14(8):1339-57.

[25] James EL, Bonsall MB, Hoppitt L, Tunbridge EM, Geddes JR, Milton AL, et al. Computer game play reduces intrusive memories of experimental trauma via reconsolidation-update mechanisms. Psychological Science. 2015; 26(8):1201-15.

[26] Holmes EA, James EL, Kilford EJ, Deeprose C. Key steps in developing a cognitive vaccine against traumatic flashbacks: visuospatial tetris versus verbal pub quiz. PloS One. 2010; 5(11):1-9.

[27] Aventin A, Houston S, Macdonald G. Utilising a computer game as a therapeutic intervention for youth in residential care: some preliminary findings on use and acceptability. Children and Youth Services Review. 2014; 47(3):362-9.

[28] Palinkas LA. Qualitative and mixed methods in mental health services and implementation research. Journal of Clinical Child \& Adolescent Psychology. 2014; 43(6):851-61.

[29] Badu E, O'Brien AP, Mitchell R. An integrative review on methodological considerations in mental health research-design, sampling, data collection procedure and quality assurance. Archives of Public Health. 2019: 77: 1-15.

[30] https://www.mentalhealth.org.uk/sites/default/files/fun damental-facts-about-mental-health-2016.pdf. Accesses 11 August 2020.

[31] Mosalanejad L, Abdollahifard S, Abdian T. Psychiatry gamification from blended learning models and efficacy of this program on students. Journal of Education and Health Promotion. 2020; 9:(68).

[32] Litvin S, Saunders R, Maier MA, Lüttke S. Gamification as an approach to improve resilience and reduce attrition in mobile mental health interventions: a randomized controlled trial. PloS one. 2020; 15(9):123.

[33] Stenros J. The game definition game: a review. Games and Culture. 2017; 12(6):499-520.

[34] Leaning M. A study of the use of games and gamification to enhance student engagement, experience and achievement on a theory-based course of an undergraduate media degree. Journal of Media Practice. 2015; 16(2):155-70.

[35] Eden S, Eshet-Alkalai Y. The effect of digital games and game strategies on young adolescents' aggression. Journal of Educational Computing Research. 2014; 50(4):449-66.

[36] Caserman P, Hoffmann K, Müller P, Schaub M, Straßburg K, Wiemeyer J, et al. Quality criteria for serious games: serious part, game part, and balance. JMIR Serious Games. 2020; 8(3):1-14.

[37] Wiemeyer J. Towards a generic framework for serious games. In international symposium on computer science in sport 2019 (pp. 193-200). Springer, Cham.

[38] Dörner R, Göbel S, Effelsberg W, Wiemeyer J. Serious games. Springer International Publishing. 2016. 
[39] Bond M, Beale R. What makes a good game? using reviews to inform design. People and computers XXIII celebrating people and technology. 2009 (pp. 418-22).

[40] Morschheuser B, Hassan L, Werder K, Hamari J. How to design gamification? a method for engineering gamified software. Information and Software Technology. 2018; 95:219-37.

[41] Desurvire H, Wiberg C. Game usability heuristics (PLAY) for evaluating and designing better games: the next iteration. In international conference on online communities and social computing 2009 (pp. 557-66). Springer, Berlin, Heidelberg.

[42] Rajanen M, Rajanen D. Usability benefits in gamification. In GamiFIN 2017 (pp. 87-95).

[43] Liu D, Santhanam R, Webster J. Toward meaningful engagement: a framework for design and research of gamified information systems. MIS Quarterly. 2017;41(4):1011-34.

[44] Floryan M, Chow PI, Schueller SM, Ritterband LM. The model of gamification principles for digital health interventions: evaluation of validity and potential utility. Journal of Medical Internet Research. 2020; 22(6):1-10.

[45] https://mindfulnessinschools.org/wpcontent/uploads/2013/09/video-games-andwellbeing.pdf. Accessed 26 September 2020.

[46] Vajawat B, Varshney P, Banerjee D. Digital gaming interventions in psychiatry: evidence, applications and challenges. Psychiatry Research. 2020.

[47] Huang B, Hew KF. Implementing a theory-driven gamification model in higher education flipped courses: effects on out-of-class activity completion and quality of artifacts. Computers \& Education. 2018; 125:254-72.

[48] Cheng VW, Davenport T, Johnson D, Vella K, Hickie IB. Gamification in apps and technologies for improving mental health and well-being: systematic review. JMIR Mental Health. 2019; 6(6):1-15.

[49] Skopljakovic E. Gaming as a social construct: towards a framework for player socialization in massive multiplayer online videogames. University of Porto Open Repository. 2019.

[50] Jennett C, Cox AL, Cairns P, Dhoparee S, Epps A, Tijs T, et al. Measuring and defining the experience of immersion in games. International Journal of HumanComputer Studies. 2008; 66(9):641-61.

[51] Taquet P, Romo L, Cottencin O, Ortiz D, Hautekeete M. Video game addiction: cognitive, emotional, and behavioral determinants for CBT treatment. Journal of Behavioral and Cognitive Therapy. 2017; 27(3):11828.

[52] Grund CK. How games and game elements facilitate learning and motivation: a literature review. Informatik 2015:1279-93.

[53] Kapp KM. The gamification of learning and instruction: game-based methods and strategies for training and education. John Wiley \& Sons; 2012.

[54] Dale S. Gamification: making work fun, or making fun of work? Business Information Review. 2014; 31(2):82-90.
[55] Alsawaier RS. The effect of gamification on motivation and engagement. The International Journal of Information and Learning Technology. 2018; 35(1):56-79.

[56] Abdul Jabbar AI, Felicia P. Gameplay engagement and learning in game-based learning: a systematic review. Review of Educational Research. 2015; 85(4):740-79.

[57] Boateng GO, Neilands TB, Frongillo EA, MelgarQuiñonez HR, Young SL. Best practices for developing and validating scales for health, social, and behavioral research: a primer. Frontiers in Public Health. 2018; 6:1-18.

[58] Kroenke K, Spitzer RL, Williams JB. The PHQ-9: validity of a brief depression severity measure. Journal of General Internal Medicine. 2001; 16:606-13.

[59] Tolks D, Sailer M, Dadaczynski K, Lampert C, Huberty J, Paulus P, et al. ONYA-The wellbeing game: how to use gamification to promote wellbeing. Information. 2019; 10(2):1-7.

[60] Lee JH, Clarke RI, Rossi S. A qualitative investigation of users' discovery, access, and organization of video games as information objects. Journal of Information Science. 2016; 42(6):833-50.

[61] Nowell LS, Norris JM, White DE, Moules NJ. Thematic analysis: striving to meet the trustworthiness criteria. International Journal of Qualitative Methods. 2017; 16(1):1-13.

[62] Braun V, Clarke V. APA handbook of research methods in psychology, Research designs: quantitative, qualitative, neuropsychological, and biological. American Psychological Association; 2012.

[63] Giakalaras MM. Gamification and storytelling. University of the Aegean. 2016.

[64] Moreau KA, Eady K, Sikora L, Horsley T. Digital storytelling in health professions education: a systematic review. BMC Medical Education. 2018; 18:1-9.

[65] De Vecchi N, Kenny A, Dickson-Swift V, Kidd S. Exploring the process of digital storytelling in mental health research: a process evaluation of consumer and clinician experiences. International Journal of Qualitative Methods. 2017; 16(1):1-13.

[66] Chan KY, Tan SL, Hew KF, Koh BG, Lim LS, Yong JC. Knowledge for games, games for knowledge: designing a digital roll-and-move board game for a law of torts class. Research and Practice in Technology Enhanced Learning. 2017; 12:1-20.

[67] Shi YR, Shih JL. Game factors and game-based learning design model. International Journal of Computer Games Technology. 2015:1-11.

[68] Schmidt-Kraepelin M, Toussaint PA, Thiebes S, Hamari J, Sunyaev A. Archetypes of gamification: analysis of mHealth apps. JMIR Mhealth and Uhealth. 2020; 8(10):1-15.

[69] Lenhart A, Duggan M, Perrin A, Stepler R, Rainie H, Parker K. Teens, social media \& technology overview. Pew Research Center. 2015. 
[70] Rusczek J. Experiences of playing massively multiplayer online role-playing games: a phenomenological exploration. . Electronic Theses and Dissertations. Duquesne University. 2015.

[71] Imran H. Evaluation of awarding badges on student's engagement in gamified e-learning systems. Smart Learning Environments. 2019; 6:1-12.

[72] Birk M, Mandryk RL. Control your game-self: effects of controller type on enjoyment, motivation, and personality in game. In proceedings of the SIGCHI conference on human factors in computing systems 2013 (pp. 685-94).

[73] Ahn SJ, Johnsen K, Ball C. Points-based reward systems in gamification impact children's physical activity strategies and psychological needs. Health Education \& Behavior. 2019; 46(3):417-25.

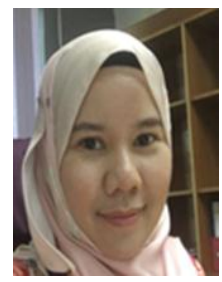

Dr Emma Nuraihan Mior Ibrahim is a senior lecturer and a postgraduate coordinator for master by coursework program at the Faculty of Computer and Mathematical Sciences (FSKM), Universiti Teknologi MARA (UiTM,) Shah Alam, Selangor, Malaysia. She was graduated from Charles Sturt University, Australia and had obtained both a master and Phd from UiTM. Her $\mathrm{PhD}$ is specialized in Human Computer Interaction (HCI). She was the recipient of the UiTM Young Lecturer Scheme scholarship for her Phd. She has been teaching in UiTM for the past 12 years. Her research interests are mainly in the area of User Experience (UX), Interaction Design, Spiritual Technology, Digital Health and Well-Being, social Computing, Cultural Informatics, Trusted Computing and Ethnography. Currently, she supervises Phd and master students within those research areas.

Email: emma@tmsk.uitm.edu.my

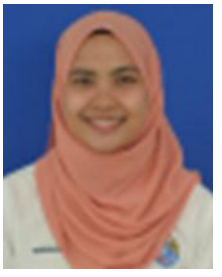

Nurulfitrie Jamali was a postgraduate student under the Master of Science in Information Technology (MSc.IT) program at the Faculty of Computer and Mathematical Sciences (FSKM), Universiti Teknologi MARA (UiTM,) Shah Alam, Selangor, Malaysia. Currently, she worked as a Junior Information Technology (IT) Officer at the Johor government state council. During her study, she was interested in the research on technology intervention in a mental health context. She was a member of the social support group for Mental Illness Awareness and Support Association (MIASA), a Mental Illness NGO support group in Malaysia. Her dream is to pursue her Phd within the same area in the future.

Email: fitriejamaly@gmail.com

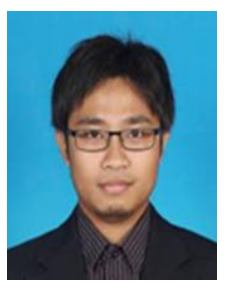

Dr Ahmad Iqbal Hakim Suhaimi is a senior lecturer at the Faculty of Computer and Mathematical Sciences (FSKM), Universiti Teknologi MARA (UiTM,) Shah Alam, Selangor, Malaysia. He obtained his degree, master and Phd from Saitama University, Japan. He was the recipient of the UiTM Young Lecturer Scheme scholarship. He is also a professional certified in Information Technology Infrastructure Library (ITIL). He taught degree and master program for subjects related to IT Infrastructure, Web Engineering, Information and Network Security, Mobile and Web Technology. Currently he supervises Phd and master students within the area of Information and Network Security.

Email: aiqbal@tmsk.uitm.edu.my 